\title{
Insulinoma-Associated Protein 1 Is a Crucial Regulator of Neuroendocrine Differentiation in Lung Cancer
}

Kosuke Fujino, ${ }^{* \dagger}$ Yamato Motooka, ${ }^{* \dagger}$ Wael A. Hassan, ${ }^{* \dagger}$ Mohamed 0. Ali Abdalla, ${ }^{\S \llbracket}$ Yonosuke Sato, ${ }^{*}$ Shinji Kudoh, ${ }^{*}$ Koki Hasegawa, ${ }^{*}$ Kanako Niimori-Kita, ${ }^{*}$ Hironori Kobayashi, ${ }^{\|}$Ichiro Kubota, ${ }^{* *}$ Joeji Wakimoto, ${ }^{* *}$ Makoto Suzuki, ${ }^{\dagger}$ and Takaaki Ito*

From the Departments of Pathology and Experimental Medicine* and Thoracic Surgery, ${ }^{\dagger}$ Graduate School of Medical Sciences, and the Department of Medical Cell Biology, ${ }^{\S}$ Institute of Molecular Embryology and Genetics, Kumamoto University, Kumamoto, Japan; the Departments of Pathology ${ }^{\ddagger}$ and Clinical Pathology, ${ }^{\uparrow}$ Faculty of Medicine, Suez Canal University, Ismaileya, Egypt; the Department of Thoracic Surgery," National Hospital Organization Kumamoto Saishunso Hospital, Kumamoto, Japan; and the Department of Thoracic Surgery and Pathology, ** National Hospital Organization Minami-Kyushu Hospital, Kagoshima, Japan

Accepted for publication August 14, 2015.

Address correspondence to Takaaki Ito, M.D., D.M.Sc., Department of Pathology and Experimental Medicine, Graduate School of Medical Sciences, Kumamoto University, Honjo 1-1-1, Chuo-ku, Kumamoto 860-8556, Japan. E-mail: takaito@kumamoto-u.ac.jp.

\begin{abstract}
Insulinoma-associated protein 1 (INSM1) is expressed exclusively in embryonic developing neuroendocrine (NE) tissues. INSM1 gene expression is specific for small-cell lung cancer (SCLC), along with achaetescute homolog-like 1 (ASCL1) and several NE molecules, such as chromogranin A, synaptophysin, and neural cell adhesion molecule 1. However, the underlying biological role of INSM1 in lung cancer remains largely unknown. We first showed that surgically resected SCLC samples specifically expressed INSM1. Forced expression of the INSM1 gene in adenocarcinoma cell lines (H358 and H1975) induced the expression of ASCL1, brain-2 (BRN2), chromogranin A, synaptophysin, and neural cell adhesion molecule 1 ; in contrast, knockdown of the INSM1 gene by siRNA in SCLC ( $\mathrm{H} 69$ and $\mathrm{H} 889$ ) decreased their expression. However, forced/knockdown expression of ASCL1 and BRN2 did not affect INSM1 expression. A chromatin immunoprecipitation study revealed that INSM1 bound to the promoter region of the ASCL1 gene. A xenotransplantation assay using tet-on INSM1 gene-transfected adenocarcinoma cell lines demonstrated that INSM1 induced NE differentiation and growth inhibition. Furthermore, we found that INSM1 was not expressed in non-small-cell lung cancer and some SCLC cell lines expressing Notch1-Hes1. By forced/ knockdown expression of Notch1 or Hes1 genes, we revealed that Notch1-Hes1 signaling suppressed INSM1, as well as ASCL1 and BRN2. INSM1, expressed exclusively in SCLC, is a crucial regulator of NE differentiation in SCLCs, and is regulated by the Notch1-Hes1 signaling pathway. (Am J Pathol 2015, 185: 3164-3177; http://dx.doi.org/10.1016/j.ajpath.2015.08.018)
\end{abstract}

Lung cancer is the leading cause of cancer-related mortality worldwide. Despite developments in the molecular analysis and understanding of lung cancer, the survival rate has not changed significantly in more than three decades. ${ }^{1}$ Small-cell lung cancer (SCLC) accounts for $10 \%$ to $15 \%$ of all lung cancer and is genetically considered to be one of the most aggressive malignant tumors. Despite a high rate of response to first-line treatment, cases inevitably relapse because of the acquisition of multidrug resistance, resulting in a 5-year survival rate of $5 \%$ to $10 \%$. $^{2}$ In recent years, focus has been on personalized treatment, as represented by epidermal growth factor receptor (EGFR)-tyrosine kinase inhibitor and anaplastic lymphoma kinase inhibitor for non-SCLC
(NSCLC). ${ }^{3,4}$ In contrast, novel target molecules of therapies for SCLC have not yet been developed. Thus, the identification of target molecules is highly anticipated.

A striking feature of SCLC is the expression of poorly differentiated neuroendocrine (NE) phenotypes; the development of this feature is thought to be correlated with tumor malignancy, which includes rapid growth, a high metastatic rate at an early stage, and the acquisition of multidrug resistance. ${ }^{5-7}$

Supported in part by a Ministry of Education, Culture, Sports, Science and Technology of Japan Grant-in-Aid for Scientific Research No. 23220010 (T.I.).

Disclosures: None declared. 
Achaete-scute homolog-like 1 (ASCL1), a proneural basic helix-loop-helix transcription factor, and brain-2 (BRN2), a POU domain transcription factor, are reported to be expressed at high frequency in SCLC. ${ }^{8-10}$ ASCL1 is required to establish the lineage of pulmonary NE cells and is involved in the survival, growth, and acquisition of chemoresistance of SCLC. ${ }^{11-13}$ As a therapeutic target of SCLC, Osada et $\mathrm{al}^{13}$ reported that knockdown of ASCL1 induces growth inhibition and apoptosis in SCLC cell lines. These findings suggest that ASCL1 could play a pivotal role in the tumorigenesis of SCLC. BRN2 is a developmental neural cell-specific transcription factor that could play a role in maintaining the $\mathrm{NE}$ phenotype of SCLC with ASCL1 $1{ }^{14}$ In addition, NE molecules [chromogranin A (CGA), synaptophysin (SYP), and neural cell adhesion molecule (NCAM)] are used as important complementary tools for the routine diagnosis of NE differentiation of lung cancer. ${ }^{715}$ These NE markers are useful for the clinical diagnosis of SCLC and have been reported as predictors of prognosis in SCLC patients. ${ }^{16}$ Although the Notch1-Hes1 signaling pathway is reported as an inhibitor of ASCL1 and NE molecules, it is largely unclear how the expression of ASCL1, BRN2, and NE molecules (CGA, SYP, and NCAM) is regulated. ${ }^{11,17-19}$

Insulinoma-associated protein 1 (INSM1) is a zinc-finger transcriptional factor originally isolated from a human insulinoma subtraction library. ${ }^{20}$ It has been reported that INSM1 plays an important role in the development of pancreatic and intestinal NE cells, adrenal medulla cells, and basal neuronal progenitor cells in the neocortex, and in the neurogenesis of the embryonic olfactory epithelium. ${ }^{21-24}$ INSM1 mRNA is abundantly expressed in fetal developing neuronal and NE tissue, but is significantly reduced or restricted in adult tissues. ${ }^{20,25,26}$ The expression of INSM1 occurs in NE tumors, including insulinoma, pituitary tumor, pheochromocytoma, medullary thyroid carcinoma, medulloblastoma, neuroblastoma, and retinoblastoma. ${ }^{20,27,28}$ Several microarray gene expression profiling experiments of SCLC cells also reported INSM1 as a highly specific marker. ${ }^{9,10}$ In addition, a Northern blotting study revealed that 30 of 31 SCLC cell lines and four NSCLC cell lines with the NE phenotype expressed INSM1 mRNA, and they showed a high concordance with other NE markers, such as CGA and L-dopa decarboxylase. ${ }^{29}$ Thus, INSM1 was identified as a highly specific NE marker and as a prominent differential marker for SCLC, along with ASCL1, a critical transcriptional factor for NE tumor of lung cancer., ${ }^{9,10}$ As a target of treatment, several groups reported the efficacy of INSM1 promoter-driven suicide gene therapy in SCLC cell lines. ${ }^{30,31}$ However, the underlying biological functions of INSM1 in lung cancer remain largely unclear.

To extend previous findings of the significance of INSM1 in lung cancer, ${ }^{30,31}$ we performed the following experimental studies. First, we examined INSM1 protein expression in 160 surgically resected cases of lung cancers [27 SCLCs, 86 adenocarcinomas (ADCs), and 47 squamous cell carcinomas (SCCs)] using immunohistochemical (IHC) staining, and in various human lung cancer cell lines using Western blot (WB) analysis to confirm the INSM1 protein expression pattern in lung cancer specimens and cell lines. Next, we used RNA interference and plasmid DNA transfection technology on lung cancer cell lines and subsequently added xenotransplantation experiments to elucidate the biological effects of INSM1 in lung cancer cell lines. Moreover, we examined mutual interactions among INSM1 and two representative NE transcription factors (ASCL1 and BRN2), and confirmed the regulatory effects of Notch1-Hes1 signaling on INSM1 expression to determine upstream and downstream regulators of INSM1. Our findings demonstrate that INSM1 is exclusively expressed in SCLC cases, regulates ASCL1, BRN2, and NE molecules (CGA, SYP, and NCAM) in SCLC cell lines, and is inhibited by the Notch1-Hes1 signaling pathway. In addition, we revealed the effect of INSM1 on the cell growth in lung cancer cell lines. Knockdown of INSM1 activates the apoptotic pathway and has an inhibitory effect on cell growth in SCLC; in contrast, forced expression of INSM1 inhibits the cell growth in NSCLC cell lines.

\section{Materials and Methods}

\section{Cell Lines}

Seven SCLC cell lines (H69, H889, SBC1, H69AR, H1688, SBC3, and SBC5), three ADC cell lines (A549, H358, and H1975), and three SCC cell lines (H226, H2170, and HCC15) were used in this study. H69, H889, H69AR, H1688, A549, H358, H1975, H226, and H2170 were purchased from ATCC (Manassas, VA), and SBC1, SBC3, and SBC5 were purchased from Japan Collection of Research Bioresources Cell Bank (Osaka, Japan). HCC15 was generously donated by Dr. Adi F. Gazdar (University of Texas Southwestern Medical Center, Dallas, TX).

\section{Tissue Samples}

Tissue samples of SCLCs $(n=27)$, ADCs $(n=86)$, and SCCs $(n=47)$, resected at the Department of Thoracic Surgery of Kumamoto University Hospital (Kumamoto, Japan) and the Department of Thoracic Surgery of National Minami-Kyushu Hospital (Kagoshima, Japan), were obtained from 160 patients for the following studies. A histological diagnosis of the samples was made according to the criteria of the World Health Organization. ${ }^{15}$ Additional sections were used for IHC staining. The study followed the guidelines of the Ethics Committee of Kumamoto University and National Minami-Kyushu Hospital.

\section{WB Analysis}

Cells were prepared for WB analysis, as previously described. ${ }^{32}$ A list of the primary antibodies used is shown in Table 1. The membrane was then washed and incubated with the respective secondary antibodies conjugated with peroxidase (Amersham Pharmacia Biotech, Buckinghamshire, UK) for 1 hour, and 
Table 1 Antibodies for WB, IF, and IHC Analyses

\begin{tabular}{|c|c|c|c|c|}
\hline Primary antibodies & Manufacturer (location) & WB & IF & $\mathrm{IHC}$ \\
\hline INSM1 $(\mathrm{C}-1)$ & Santa Cruz Biotechnology (Santa Cruz, CA) & $1: 5000$ & $1: 100$ & 1:100 \\
\hline ASCL1 (556604) & BD Biosciences Pharmingen (San Jose, CA) & 1:1000 & & \\
\hline BRN2 (GTX114650) & Gene Tex (San Antonio, TX) & $1: 1000$ & & \\
\hline CGA $(H-300)$ & Santa Cruz Biotechnology & 1:1000 & $1: 100$ & $1: 100$ \\
\hline SYP (NCL-SYNAP-299) & Novocastra Laboratories Ltd (Newcastle upon Tyne, UK) & 1:1000 & $1: 50$ & $1: 50$ \\
\hline NCAM (NCL-CD56-1B6) & Novocastra Laboratories Ltd & 1:1000 & $1: 50$ & $1: 50$ \\
\hline P-H3 (Ser10) & Millipore (Billerica, MA) & 1:1000 & & \\
\hline Cas3 (9662) & Cell Signaling & 1:1000 & & \\
\hline C-Cas3 (9661) & Cell Signaling & $1: 1000$ & & \\
\hline $\mathrm{Bcl}-2(50 \mathrm{E} 3)$ & Cell Signaling & $1: 1000$ & & \\
\hline Cyclin D1 (PM-9104) & Neomarkers Inc. (Fremont, CA) & $1: 1000$ & & \\
\hline Normal rabbit IgG (sc-2027) & Santa Cruz Biotechnology & $1: 1000$ & $1: 100$ & 1:100 \\
\hline
\end{tabular}

Manufacturers, quantities, and working dilutions are indicated.

ASCL1, achaete-scute homolog-like 1; BRN2, brain-2; C-Cas3, cleaved caspase 3; CGA, chromogranin A; IF, immunofluorescence; IHC, immunohistochemistry; INSM1, insulinoma-associated protein 1; NCAM, neural cell adhesion molecule; P-H3, phospho-histone H3; SYP, synaptophysin; WB, Western blot.

the immune complex was visualized with the electrochemiluminescence system (Santa Cruz Biotechnology, Santa Cruz, CA).

\section{IFA Data}

The cells were treated as previously described. ${ }^{32}$ The slides were heated using an autoclave in $0.01 \mathrm{~mol} / \mathrm{L}$ citrate buffer $(\mathrm{pH}$ 7.0) (for CGA, SYP, and NCAM) for antigen retrieval, but this was not necessary to perform INSM1 immunofluorescence analysis (IFA) staining. A list of the primary antibodies used is provided in Table 1. Cells were incubated with the appropriate secondary antibodies (Alexa Fluor; Molecular Probes, Eugene, OR) and examined using a fluorescent microscope (Olympus, Tokyo, Japan). The specificity of immunolabeling of each antibody was tested by using normal mouse IgG (Santa Cruz Biotechnology) and normal rabbit IgG (Santa Cruz Biotechnology), and no staining was observed.

\section{IHC Staining}

Formalin-fixed, paraffin-embedded specimens were cut into sections (4 $\mu \mathrm{m}$ thick) and mounted onto MASGP-coated slides (Matsunami Glass Ind, Osaka, Japan). After being deparaffinized and rehydrated, the sections were heated using an autoclave in $0.01 \mathrm{~mol} / \mathrm{L}$ citrate buffer (pH 7.0) for antigen retrieval. The sections were incubated with $0.3 \% \mathrm{H}_{2} \mathrm{O}_{2}$ in absolute methanol for 20 minutes to block endogenous peroxidase activity. Then, the sections were incubated with Protein Block Serum Free Reagent (Dako, Glostrup, Denmark) for 30 minutes to block nonspecific staining. After this blocking step, the sections were incubated with the primary antibodies shown in Table 1 at $4{ }^{\circ} \mathrm{C}$ overnight. This was followed by sequential 1-hour incubations with the secondary antibodies (En Vision+ System-HRP-Labeled Polymer; Dako) and

Table 2 List of Primers Used in Quantitative RT-PCR

\begin{tabular}{|c|c|c|}
\hline Target & Sequence & $\begin{array}{l}\text { Product } \\
\text { size } \\
\text { (bp) }\end{array}$ \\
\hline INSM1 & $\begin{array}{l}\text { F: 5'-CAGTGTGCGGAGAGTCGTT-3' } \\
\text { R: 5'-ACCTGTCTGTTTTCGGATGG-3' }\end{array}$ & 166 \\
\hline ASCL1 & $\begin{array}{l}\text { F: 5'-CGGCCAACAAGAAGATGAGT-3' } \\
\text { R: 5'-GCCATGGAGTTCAAGTCGTT-3' }\end{array}$ & 169 \\
\hline BRN2 & $\begin{array}{l}\text { F: 5'-ATGTGCAAGCTGAAGCCTTT-3' } \\
\text { R: 5'-СTCACCACСТCСТTCTCCAG-3' }\end{array}$ & 236 \\
\hline CGA & $\begin{array}{l}\text { F: 5'-CCTGTCAGCCAGGAATGTTT-3' } \\
\text { R: 5'-CATCCTTGGATGATGGCTCT-3' }\end{array}$ & 235 \\
\hline SYP & $\begin{array}{l}\text { F: 5'-TGCCAACAAGACCGAGAGTGA-3' } \\
\text { R: } 5^{\prime}-\text { CCACATGAAGGCGAACACAGC-3' }\end{array}$ & 289 \\
\hline NCAM & $\begin{array}{l}\text { F: 5'-GGAACCCAGTGCACCTAAGCT-3' } \\
\text { R: 5'-CGCTCGGTACCTGACCAGAT-3' }\end{array}$ & 125 \\
\hline GAPDH & $\begin{array}{l}\text { F: 5'-CGCTCTCTGCTCCT-3' } \\
\text { R: 5'-CCATGGTGTCTGAGCGATGT-3' }\end{array}$ & 81 \\
\hline $\begin{array}{l}\text { ASH1 } \\
\text { promoter } \\
\text { (for ChIP) }\end{array}$ & $\begin{array}{l}\text { F: 5'-CAAGAGAGCGCAGCCTTAGT-3' } \\
\text { R: 5'-CTGGCGCCTTCTTGTTTCTA-3' }\end{array}$ & 113 \\
\hline $\begin{array}{l}\text { Negative } \\
\text { control } \\
\text { (for (hIP) }\end{array}$ & $\begin{array}{l}\text { F: 5'-TTGGAGAGAGGTAGGGCAGA-3' } \\
\text { R: 5'-AAGAGCCCCACTTTGGAAAT-3' }\end{array}$ & 96 \\
\hline
\end{tabular}

ASCL1, achaete-scute homolog-like 1; BRN2, brain-2; CGA, chromogranin A; ChIP, chromatin immunoprecipitation; F, forward; GAPDH, glyceraldehyde3-phosphate dehydrogenase; INSM1, insulinoma-associated protein 1; NCAM, neural cell adhesion molecule; R, reverse; SYP, synaptophysin. 


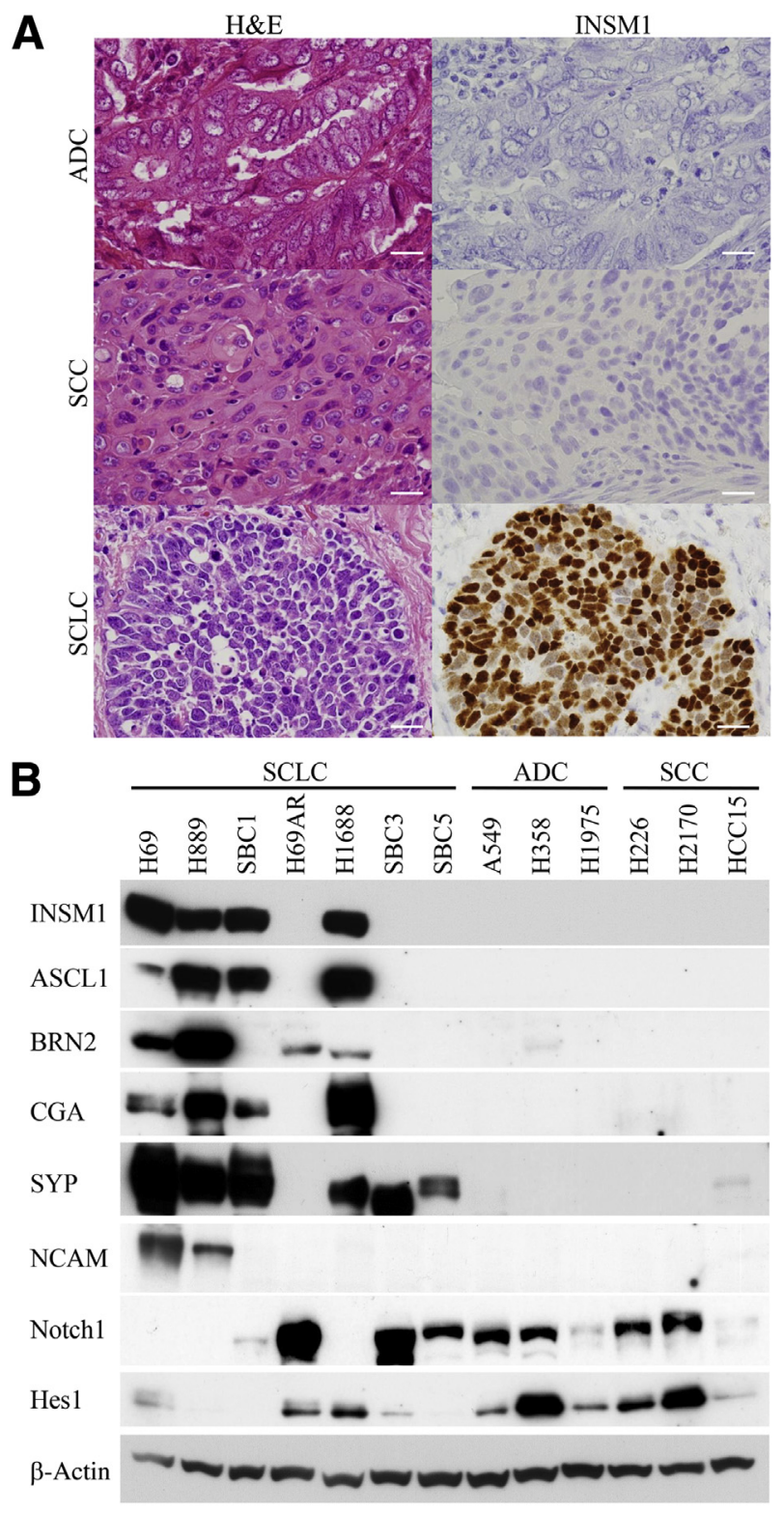

Figure 1 Small-cell lung cancer tissues and cell lines exclusively express insulinoma-associated protein 1 (INSM1). A: Immunohistochemical staining for INSM1 was performed in 27 small-cell lung carcinoma (SCLC), 86 adenocarcinoma (ADC), and 47 squamous cell carcinoma (SCC) specimens that had been surgically resected. All SCLC cases were positive for INSM1, but all non-SCLC (NSCLC) cases were negative. Representative images are shown. B: Western blot analysis was conducted using lung cancer cell lines, including SCLC, ADC, and SCC. Expression of INSM1, achaete-scute homolog-like 1 (ASCL1), brain-2 (BRN2), chromogranin A (CGA), synaptophysin (SYP), neural cell adhesion molecule (NCAM), Notch1, and hairy and enhancer of split-1 (Hes1) in lung cancer cell lines. Four of seven SCLC cell lines express INSM1, ASCL1, and CGA with similar patterns. BRN2, SYP, and NCAM is expressed in some SCLC cell lines, whereas none of these molecules is detected in the NSCLC cell lines examined. Notch1 is detected in the cell lines that did not express INSM and ASCL1. Hes1 is expressed similarly to Notch1. $\beta$-Actin served as an internal control. Scale bar $=$ $20 \mu \mathrm{m}(\mathbf{A})$. H\&E, hematoxylin and eosin.

visualization with the Liquid DAB + Substrate Chromogen System (Dako). All slides were counterstained with hematoxylin for 30 seconds before being dehydrated and mounted. The specificity of immunolabeling of each antibody was tested by using normal mouse $\operatorname{IgG}$ (Santa Cruz Biotechnology) and normal rabbit IgG (Santa Cruz Biotechnology), and no staining was observed. In addition, we confirmed that as positive IHC controls for INSM1, pancreatic islets and insulinoma were positive for INSM1.

\section{Transfection with siRNA}

siRNAs for INSM1, ASCL1, BRN2, Notch1, Hes1 mRNA, and negative control (scrambled random siRNA) were purchased from Santa Cruz Biotechnology and transfected into cells at a concentration of $20 \mathrm{nmol} / \mathrm{L}$ by using an electroporator (NEPA21 pulse generator; Nepa Gene, Chiba, Japan), as described in the manufacturer's instructions. The cells were harvested at 48 hours after transfection.

\section{Cell Counting Assay}

H69 and H889 cells that were transfected with siRNA as a negative control, INSM1, and BRN2 were seeded at equivalent densities $\left(2.5 \times 10^{5}\right.$ cells $\left./ \mathrm{mL}\right)$ in 6 -well plates. At 24 -hour intervals, cells were trypsinized and then counted using a TC20 Automated Cell Counter (BioRad Laboratories, Richmond, CA). The experiments were repeated separately in triplicate to confirm reproducibility.

\section{Plasmid Construction and Transfection}

\section{INSM1-Expressing Vector}

To construct pTRE3G-ZsGreen1-INSMI, INSMI cDNA was obtained from the pCMV6-XL5-INSM1 vector (OriGene, Rockville, MD) and inserted into the Mlu1 and BamHI sites of the pTRE3G-ZsGreen1-mock vector (Clontech, Mountain View, CA). The tet-on INSMItransfected H358 and H1975 cells were established by using this vector and the tet-on system, as described below.

\section{Notch1-Expressing Vector}

Human Notch1 intracellular domain cDNA, a fragment (5262 to 7665) of the human Notchl gene, was PCR amplified using cDNA from $\mathrm{H} 358$ cells and cloned into the Mlu1 and BamHI sites of the pTRE3G-ZsGreen1-mock vector (Clontech). The tet-on Notchl-transfected H69 and H889 cells were established by using this vector and the teton system, as described below.

\section{Hes1-Expressing Vector}

To construct pTRE3G-ZsGreen1-Hes 1, a fragment (1 to 843) of the human Hesl gene was PCR amplified using cDNA from $\mathrm{H} 358$ cells and cloned into the Mlu1 and BamHI sites of the pTRE3G-ZsGreen1-mock vector (Clontech). The tet-on Hes1-transfected H69 and H889 cells were obtained by using this vector and the tet-on system, as described below. 
Table 3 Results of Immunohistochemical Staining of Human Lung Carcinoma Surgically Resected Samples

\begin{tabular}{|c|c|c|c|c|c|c|c|}
\hline \multirow[b]{3}{*}{ Variable } & \multirow[b]{3}{*}{$\begin{array}{l}\text { Type of } \\
\text { result }\end{array}$} & \multicolumn{4}{|c|}{$\underline{\operatorname{SCLC}(n=27)}$} & \multicolumn{2}{|c|}{$\operatorname{NSCLC}(n=133)$} \\
\hline & & \multirow[b]{2}{*}{$\begin{array}{l}\text { Pure } \\
(n=19)\end{array}$} & \multicolumn{3}{|c|}{ Combined SCLC $(n=8)$} & \multirow[b]{2}{*}{$\operatorname{ADC}(n=86)$} & \multirow[b]{2}{*}{$\operatorname{SCC}(n=47)$} \\
\hline & & & $\begin{array}{l}\mathrm{SCLC} \\
\text { component } \\
(n=8)\end{array}$ & $\begin{array}{l}\mathrm{ADC} \\
\text { component } \\
(n=3)\end{array}$ & $\begin{array}{l}\text { SCC } \\
\text { component } \\
(n=5)\end{array}$ & & \\
\hline \multirow[t]{2}{*}{ INSM1 } & + & 19 & 8 & 0 & 0 & 0 & 0 \\
\hline & - & 0 & 0 & 3 & 5 & 86 & 47 \\
\hline CGA & - & 5 & 3 & 3 & 5 & 86 & 47 \\
\hline \multirow[t]{2}{*}{ SYP } & + & 11 & 6 & 0 & 0 & 0 & 0 \\
\hline & - & 8 & 2 & 3 & 5 & 86 & 47 \\
\hline \multirow[t]{2}{*}{ NCAM } & + & 13 & 4 & 0 & 0 & 0 & 0 \\
\hline & - & 6 & 4 & 3 & 5 & 86 & 47 \\
\hline Notch1 & + & 0 & 0 & 3 & 5 & 86 & 47 \\
\hline
\end{tabular}

ADC, adenocarcinoma; CGA, chromogranin A; INSM1, insulinoma-associated protein 1; NCAM, neural cell adhesion molecule; NSCLC, non-small-cell lung cancer; SCC, squamous cell carcinoma; SCLC, small-cell lung cancer; SYP, synaptophysin; +, positive; -, negative.

\section{ASCL1-Expressing Vector}

Human ASCL1 cDNA was obtained from the pOTB7-ASCL1 vector (RIKEN BRC through the National Bio-Resource Project of MEXT, Tsukuba, Japan) and inserted into the EcoRI and XbaI sites of the pCMV6-XL5-mock vector (OriGene). The ASCL1-transfected H358 and H1975 cells were obtained by transfection with this vector using an electroporator (Nepa Gene), as described in the manufacturer's instructions.

\section{BRN2-Expressing Vector}

To construct pCMV6-XL5-BRN2, a BRN2 expression vector, a fragment (from 1 to 1332) of the human BRN2 was PCR amplified using cDNA from H69 cells, and cloned into the EcoRI and XbaI sites of the pCMV6-XL5-mock vector. The BRN2-transfected H358 and H1975 cells were obtained by transfection with this vector using an electroporator (Nepa Gene), as described in the manufacturer's instructions.

\section{Tet-0n System}

The Tet-On 3G Inducible Expression System with ZsGreen1 (Clontech) was used to establish the tet-on cell lines, according to the manufacturer's instructions, to avoid difficulty in obtaining stable cell lines because of unexpected growthinhibitory effects caused by the transfected genes. In brief, clones expressing tet-on $3 \mathrm{G}$ transactivator protein were obtained by the transfection of H69, H889, H358, and H1975 with the pCMV-Tet3G vector (Clontech). Selected positive clones were cultured in each medium containing G418 $(500 \mu \mathrm{L} / \mathrm{mL}$; Clontech). Selected clones were then cotransfected with pTRE3G-Zsgreen1-INSM1 (for H358 and H1975), pTRE3GZsgreen1-Notch1 (for H69 and H889), pTRE3G-Zsgreen1Hesl (for H69 and H889), and Linear Puromycin Marker (Clontech). Transfected cells were selected with $5 \mu \mathrm{g} / \mathrm{mL}$ puromycin (Clontech). The resistant clones were expanded and examined for the induction of each protein and ZsGreen1 on the addition of $0.5 \mu \mathrm{g} / \mathrm{mL}$ doxycycline (Dox) by WB analysis, quantitative RT-PCR, and IFA. Cells were transfected by using a NEPA21 pulse generator (Nepa Gene), as described in the manufacturer's instructions.

\section{Quantitative RT-PCR}

The Fast Pure RNA Kit (Takara Bio, Shiga, Japan) was used to isolate total RNA from each cell line. cDNA was produced using a ReverTra Ace qPCR RT-Kit (Toyobo, Osaka, Japan), according to the manufacturer's instructions. cDNA was subjected to quantitative SYBR Green real-time PCR by using SYBR Premix Ex Taq II (Takara Bio). A list of the specific primers is provided in Table 2. Real-time quantitative PCR was performed with a Thermal Cycle Dice Real-Time System (Takara Bio) by using 40 cycles of a three-stage program with the following conditions: 2 seconds at $95^{\circ} \mathrm{C}, 10$ seconds at $60^{\circ} \mathrm{C}$, and 15 seconds at $72^{\circ} \mathrm{C}$, as recommended by the manufacturer. The products were quantified during the initial exponential phase of amplification above the baseline. Data were obtained from triplicate reactions. The means and SDs of the copy number were normalized to the value for glyceraldehyde-3-phosphate dehydrogenase mRNA.

\section{ChIP Assay}

A PCR primer was designed to cover the promoter region on $A S C L 1$, and another PCR primer for a non-promoter region on ASCL1 was designed as a negative control. The arrangements of the primers are shown in Table 2. Chromatin was immunoprecipitated using anti-INSM1 and normal rabbit IgG (Santa Cruz Biotechnology). Approximately $2 \times 10^{6}$ cells (H69, H889, H358, and H1975) were used per chromatin immunoprecipitation (ChIP) reaction. In brief, cells were harvested, fixed in $1 \%$ formaldehyde, and sonicated to produce chromatin 

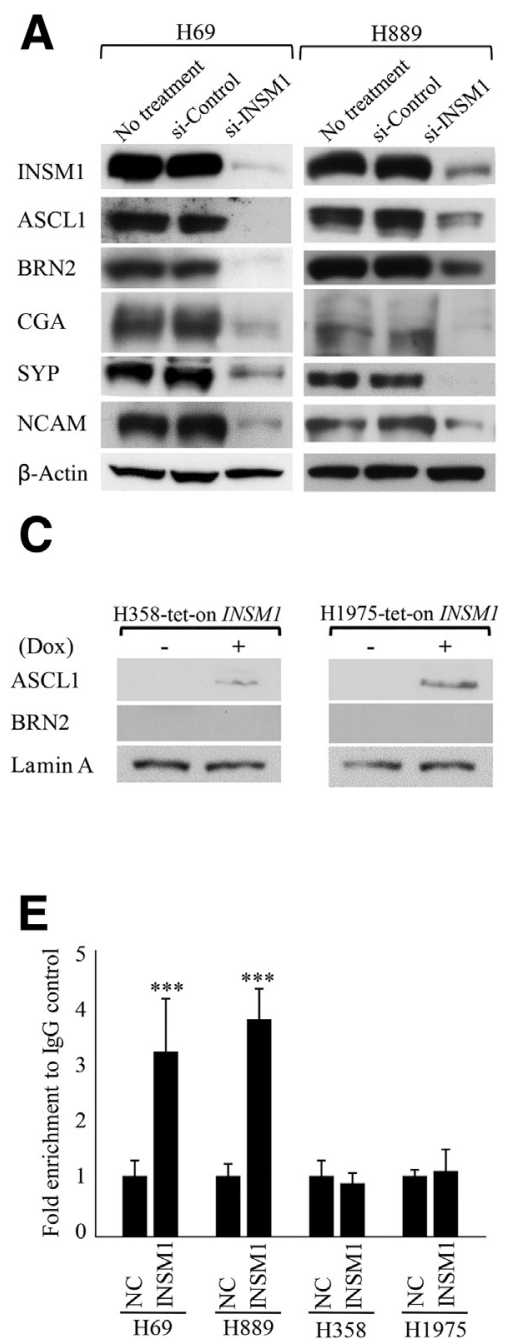

fragments 300 to $500 \mathrm{bp}$ in length. The precipitated DNA was extracted using phenol-chloroform and then purified. The fold enrichment was calculated as the difference between each sample and the negative control using quantitative RT-PCR analysis, as described above. Individual assays were repeated three times to confirm the reproducibility of the experiment.

\section{Tumor Xenograft Growth in Vivo and Histopathological Evaluation}

The tet-on H358 and H1975, which express INSM1 in the presence of Dox, were established by using a Tet-On 3G Inducible Expression System with ZsGreen1 (Clontech). A total of $2 \times 10^{6}$ cells were injected s.c. into the back of 10 mice $\left[\mathrm{Rag}^{-1-}: \mathrm{Jak}^{-1-}\right.$ mice; a generous gift from Prof. Seiji Okada (Kumamoto University)]. After tumor formation was confirmed after 3 weeks, the mice were divided into two groups, in which the average tumor sizes were similar (approximately $1000 \mathrm{~mm}^{3}$ ). One group was given drinking water supplemented with $4 \mathrm{mg} / \mathrm{L}$ Dox, and the other group was given normal water. Five weeks after the first injection, the tumors were removed and measured. The samples were
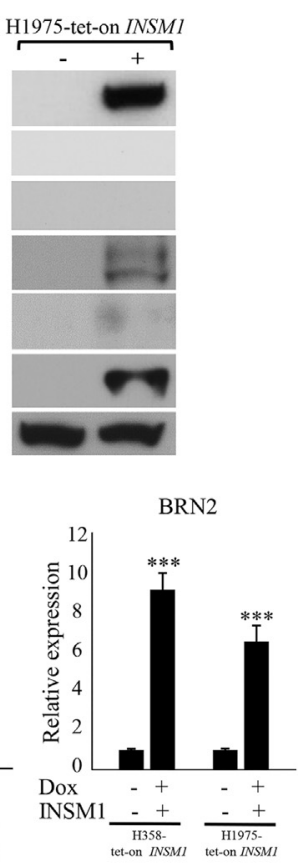

Figure 2 Insulinoma-associated protein 1 (INSM1) is involved in neuroendocrine (NE) differentiation of lung cancer cells. A: Western blot (WB) reveals that knockdown of INSM1 in small-cell lung carcinoma (SCLC) cell lines $\mathrm{H} 69$ and $\mathrm{H} 889$ significantly reduces the expression of achaetescute homolog-like 1 (ASCL1), brain-2 (BRN2), chromogranin A (CGA), synaptophysin (SYP), and neural cell adhesion molecule (NCAM). B: INSM1 expression was induced by doxycycline (Dox) treatment in H358-tet-on INSM1 and H1975-tet-on INSM1 cells. WB analysis reveals that NE molecules increase by the forced expression of INSM1 in the cells, although ASCL1 and BRN2 are not detected in whole-cell lysates from these cells. C: Nuclear proteins obtained from the Dox-treated H358-teton INSM1 and H1975-tet-on INSM1 cells applied to WB analyses reveal that ASCL1 increases in the cells with the forced expression of INSM1. However, BRN2 is not detected. D: Quantitative RT-PCR (RT-qPCR) analysis to examine the changes in the expression of ASCL1 and BRN2 mRNA by the forced expression of INSM1. ASCL1 and BRN2 mRNA increases by the forced expression of INSM1. E: Chromatin immunoprecipitation-real-time quantitative PCR was applied to clarify whether INSM1 binds directly to the promoter region of ASCL1. Note the binding activity of INSM1 in $\mathrm{H} 69$ and H899 SCLC cell lines, but not in H358 and H1975 ADC cell lines. All analyses were performed in triplicate. $\beta$-Actin was used as an internal control in WB analysis using whole-cell lysates, and LaminA was used in WB analysis using nuclear protein extracts. Glyceraldehyde-3-phosphate dehydrogenase was also used in RT-qPCR analysis. Data are given as means \pm SD (D and $\mathbf{E})$. ${ }^{* * *} P<0.001$. NC, non-specific control; Si, small interfering.

fixed with $10 \%$ formalin and embedded in paraffin. Tissue sections were stained with hematoxylin and eosin, and additional sections were IHC stained, as described above. All animal experiments were conducted in accordance with the guidelines of the Animal Care and Use Committee of Kumamoto University.

\section{Statistical Analysis}

All data were obtained from independent experiments, and are expressed as the means \pm SD of triplicate determinations. The differences in the mean values between the two groups were statistically analyzed using $t$-test. SPSS version 18 (SPSS Inc., Chicago, IL) was used for statistical analyses. $P<0.05$ was considered significant.

\section{Results}

INSM1 Is Expressed in SCLC Tissue Sections and SCLC Cell Lines

Previous studies revealed that INSM1 expression is specific for SCLC and NSCLC with NE phenotypes. ${ }^{29}$ However, to 


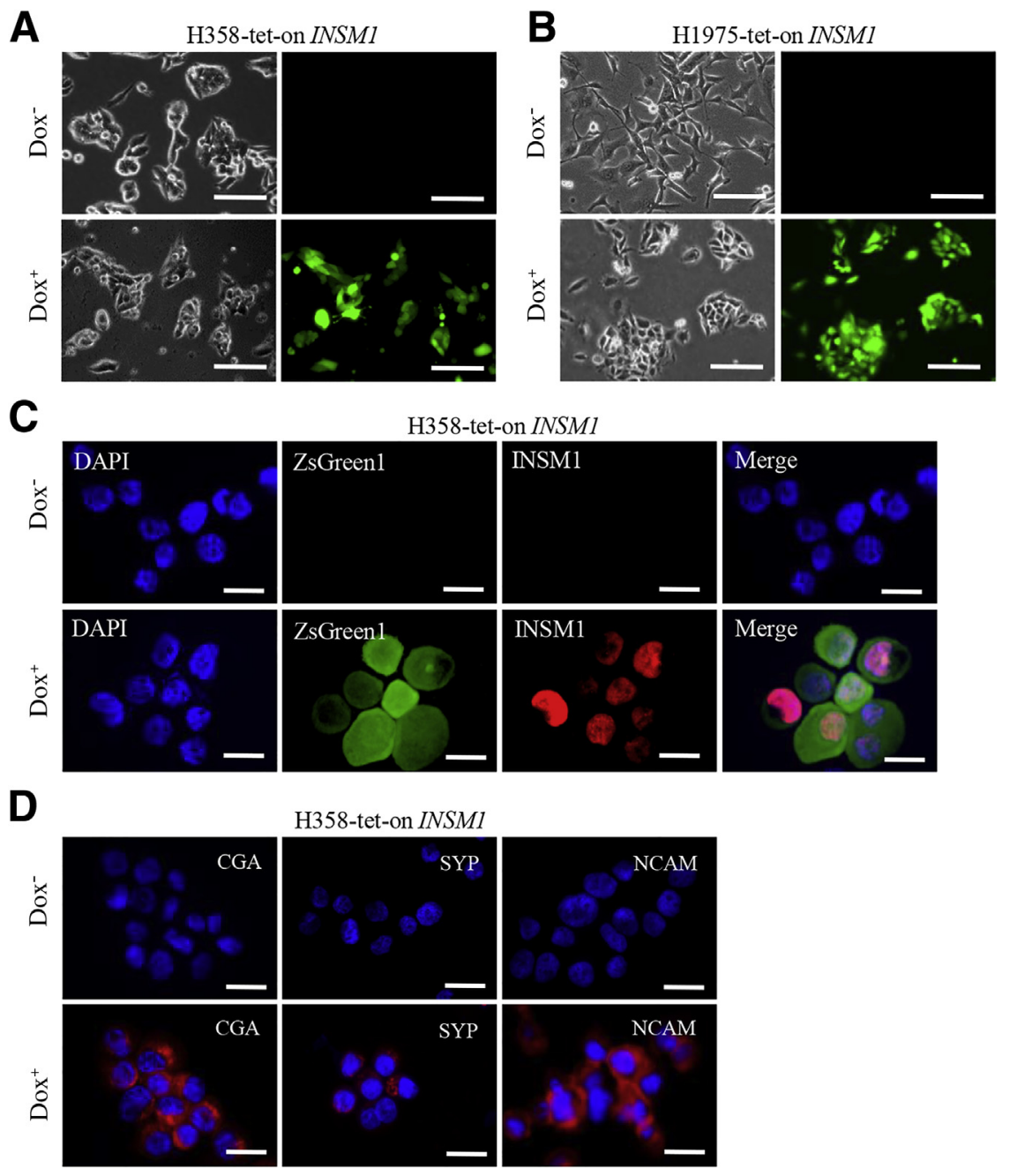

Figure 3 Immunofluorescence staining reveals insulinoma-associated protein 1 (INSM1) and neuroendocrine (NE) molecules in doxycycline (Dox)-treated H358-tet-on INSM1 and H1975-teton INSM1 ADC cells. Green fluorescence (ZsGreen1) is induced in H358-tet-on INSM1 (A) and H1975tet-on INSM1 cells treated with Dox (B). C: INSM1 is detected in cell nuclei on the presence of Dox. Dox regulates the expression of INSM1 and ZsGreen1 in H358-tet-on INSM1 cells. Representative immunofluorescence images are shown. D: Positive immunofluorescence staining for chromogranin A (CGA), synaptophysin (SYP), and neural cell adhesion molecule (NCAM; Alexa Fluor 568, red) is detected in the INSM1-expressing cells. Scale bars: $100 \mu \mathrm{m}$ (A and B); $20 \mu \mathrm{m}$ (C and D).

our knowledge, no study has analyzed the expression of INSM1 protein. To examine the INSM1 protein expression pattern, we stained surgically resected lung cancer tissues (27 SCLCs, 86 ADCs, and 47 SCCs) immunohistologically for INSM1 (Figure 1A) and performed WB analysis in 13 lung cancer cell lines (seven SCLCs, three ADCs, and three SCCs) (Figure 1B). By IHC, INSM1 was expressed exclusively in all pure SCLC specimens and the SCLC component in combined SCLC specimens (Table 3). In addition, WB analysis revealed that INSM1 protein was expressed in four of seven SCLC cell lines, but was not expressed in NSCLC cell lines (Figure 1B). The expression of ASCL1, BRN2, Notch1, Hes1, and NE marker molecules (CGA, SYP, and NCAM) in lung cancer cell lines was also confirmed by WB analysis (Figure 1B).

Four of seven SCLC cell lines showed the same expression patterns of INSM1, ASCL1, and CGA. Although their expression patterns were not similar, BRN2 and other NE marker molecules (SYP and NCAM) were exclusively expressed in SCLC cell lines.

In contrast, by IHC, Notch1 was expressed in all of the NSCLC specimens and the NSCLC component of combined SCLC specimens (Table 3 and Supplemental Figure S1). WB analysis of lung cancer cell lines revealed that Notch1 was strongly expressed in NSCLC cell lines and in SCLC cell lines that did not have INSM1 and ASCL1 expression. This implies that Notch1 might have a biological function that opposes those of INSM1 and ASCL1. Although Hes1 was reported to be a key effector of the NE network in the Notch1 pathway, ${ }^{11}$ Hes1 expression was not always consistent with the Notch1 expression pattern, suggesting that various pathways could exist. We summarize the results of IHC staining of INSM1, CGA, SYP, NCAM, and Notch1 in Table 3.

INSM1 Is a Crucial Regulator of ASCL1, BRN2, and NE Molecules in Lung Cancer Cells

To investigate the biological effect of INSM1 in lung cancer cell lines, we first conducted INSM1 knockdown experiments using RNA interference in H69 and H889 cells as representatives of SCLC cells that express INSM1 (Figure 1B and Figure 2A). Knockdown of INSM1 expression in H69 and H889 cells resulted in significant reduction of the protein expression of ASCL1, BRN2, and NE molecules (CGA, SYP, and NCAM) (Figure 2A). 
A

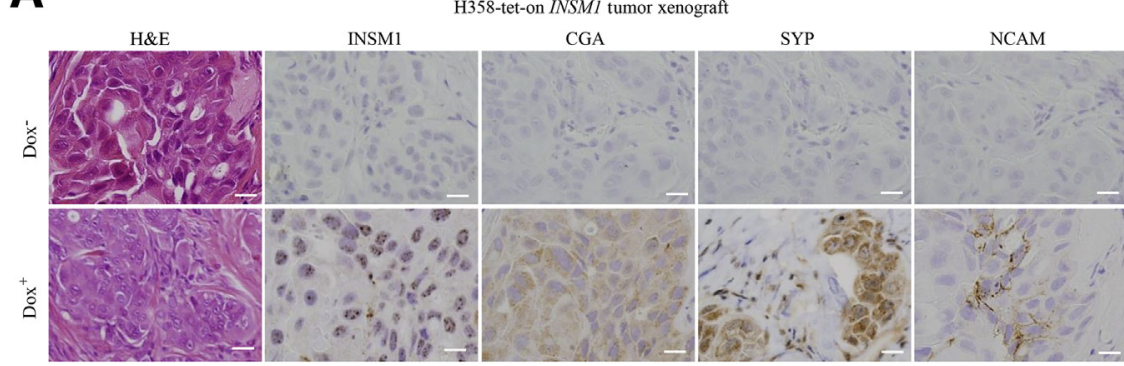

B

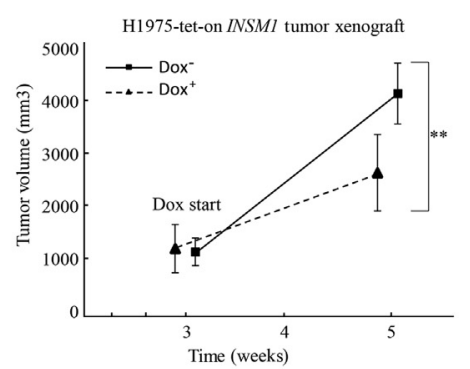

D

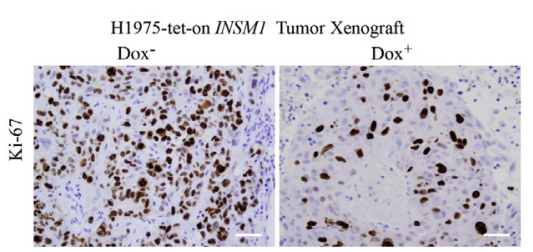

$\mathbf{F}$

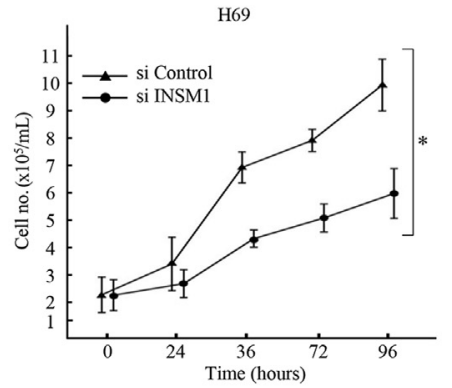

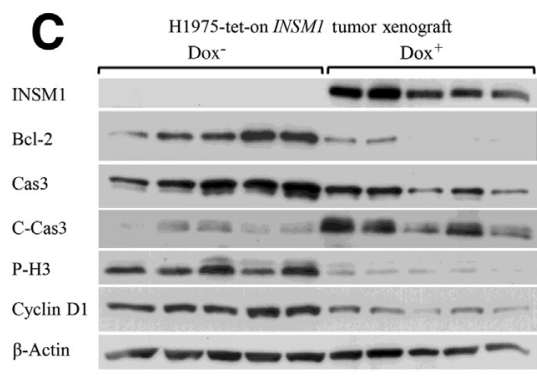

E
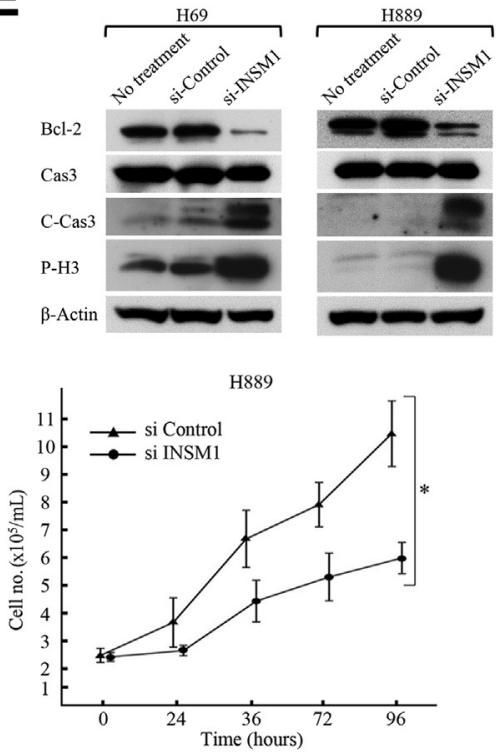

Figure $\mathbf{4}$ Insulinoma-associated protein 1 INSM1) does not change tumor histology, but is involved in neuroendocrine (NE) differentiation and cell proliferation and apoptosis. Stable cell lines (H358-tet-on INSM1 and H1975-tet-on INSM1) that expressed INSM1 on the addition of doxycycline (Dox) were transplanted s.c. in the back of 10 immunodeficient mice. When the s.c. tumors were detected after 3 weeks (average size, approximately $1000 \mathrm{~mm}^{3}$ ), the mice were divided into two groups. One group $\left(\mathrm{Dox}^{+}\right)$ was given drinking water supplemented with Dox, whereas the other group was given normal water. Five weeks after the first injection, the s.c. tumors were obtained for morphological study, followed by fixation with $10 \%$ formalin, paraffin embedding, and Western blot (WB) analysis. A: Adjacent sections subjected to hematoxylin and eosin (H\&E) and immunohistochemical staining from the mice treated without $\left(\operatorname{Dox}^{-}\right)$or with Dox $\left(\operatorname{Dox}^{+}\right)$. Although the NE molecules are detected immunohistochemically in Dox ${ }^{+}$tumors, the histology of the Dox ${ }^{+}$tumors forced to express INSM1 does not change to neuroendocrine morphology. B: Forced expression of INSM1 [in H1975-tet-on INSM1 (Dox ${ }^{+}$cells)] significantly suppresses tumor growth compared with that of H1975-tet-on INSM1 (Dox ${ }^{-}$). C: WB analysis of cell proliferation and apoptotic markers in the xenografted tumors that originated from the H1975-teton INSM1 cells with or without Dox treatment. Forced expression of INSM1 reduces phospho-histone $\mathrm{H} 3$ ( $\mathrm{P}$ $\mathrm{H} 3$ ), Bcl-2, caspase-3 (Cas3), and cyclin D1, but increases cleaved caspase-3 (C-Cas3). D: Ki-67 labeling index in Dox ${ }^{+}$tumor decreases significantly: Dox versus $\mathrm{Dox}^{+}, 77.6 \pm 6.2$ versus $33.2 \pm 9.2$ $(P<0.01)$. E: WB analysis reveals that the knockdown of INSM1 expression facilitates the apoptotic pathway and proliferative activity. Knockdown of INSM1 expression increases $\mathrm{C}-\mathrm{Cas} 3$ and $\mathrm{P}-\mathrm{H} 3$, but $\mathrm{BCl}-2$ decreases in SCLC cell lines (H69 and H889). F: Cell counting assay reveals that knockdown of INSM1 expression suppresses cell growth in SCLC cell lines (H69 and H889). ${ }^{*} P<0.05,{ }^{*} P<0.01 . N=5$ per group (B and F). Scale bars: $20 \mu \mathrm{m}$ (A); $50 \mu \mathrm{m}$ (D). CGA, chromogranin A; NCAM, neural cell adhesion molecule; si, small interfering; SYP, synaptophysin.
Next, to confirm that INSM1 actually affects ASCL1, BRN2, and NE molecules, we performed INSM1 transfection experiments and obtained stable cell lines that express it only in the presence of Dox using the tet-on inducible expression system applied to $\mathrm{H} 358$ and $\mathrm{H} 1975$ cells, which are representatives of NSCLC cell lines without the expression of INSM1 and other NE molecules. The expression of ASCL1 and NE molecules was induced by the forced expression of INSM1 (Figure 2, B and C). Although WB analysis did not detect the induction of BRN2 protein, an increase of the BRN2 mRNA expression level was detected by quantitative RT-PCR (Figure 2D). These results suggested that INSM1 is strongly involved in ASCL1 expression, so we performed a ChIP assay to find out whether ASCL1 is a direct target of INSM1 or not. The results demonstrated that INSM1 binds to the promoter region of
ASCL1 directly (Figure 2E). In addition, the induction of the NE molecule proteins was confirmed by IFA analysis in vitro (Figure 3) and IHC staining in the tumor tissue sections formed from xenotransplanted cells (Figure 4A). Although the forced expression of INSM1 induced NE differentiation in lung cancer cell lines, the histological pattern did not change to NE morphology (Figure 4A).

\section{The Effect of INSM1 on Proliferation and Apoptosis in} Lung Cancer Cell Lines

The sizes of xenotransplanted tumors from tet-on INSMItransfected H1975 cells with Dox $\left(\right.$ Dox $\left.^{+}\right)$were significantly smaller than those from tet-on INSM1-transfected H1975 cells without Dox $\left(\right.$ Dox $^{-}$) (Figure 4B). Moreover, WB analysis showed that the forced expression of INSM1 reduced 

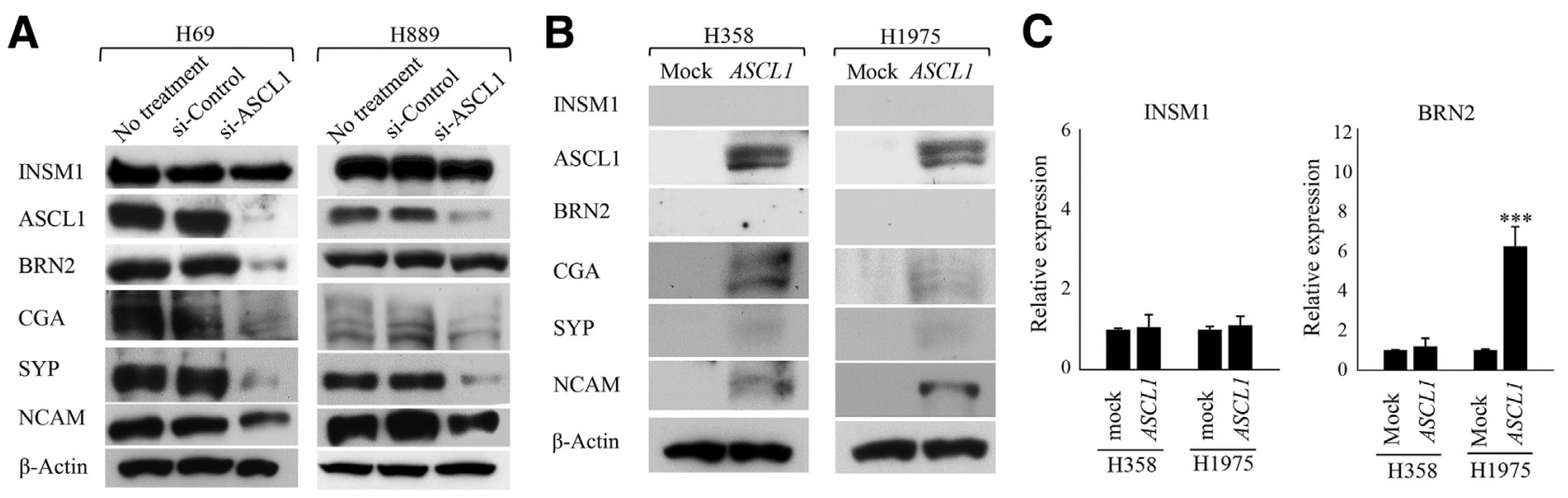

Figure 5 Achaete-scute homolog-like 1 (ASCL1) does not affect insulinoma-associated protein 1 (INSM1) expression, but is involved in the expression of neuroendocrine (NE) molecules and brain-2 (BRN2) in the lung cancer cell lines. ASCL1 was knocked down or transiently expressed. In the latter experiments, human ASCL1 CDNA was inserted into pCMV6-XL5-mock vector. H358 and H1975 adenocarcinoma (ADC) cell lines were transiently transfected with pCMV6-XL5ASCL1 by electroporation. Control cells were transfected with the mock vector. All analyses were performed in triplicate. $\beta$-Actin was used as an internal control in the Western blot (WB) analysis of whole-cell lysates, and Lamin-A was used in the WB analysis of nuclear protein extracts. Glyceraldehyde-3-phosphate dehydrogenase was also used in quantitative RT-PCR (RT-qPCR) analysis. A: Knockdown of the ASCL1 gene does not affect INSM1 expression, but reduces the NE molecules in $\mathrm{H} 69$ and $\mathrm{H} 889$ cells. Suppression of BRN2 is observed only in H69 cells with the siRNA. B: WB analyses reveal that the forced expression of ASCL1 induces NE molecules in ADC cell lines (H358 and H1975), although INSM1 and BRN2 are negative. C: RT-qPCR studies reveal that INSM1 mRNA is not induced by the forced expression of ASCL1 in both cell lines, but BRN2 mRNA is induced only in the transient ASCL1-transfected H1975 cells. Data are given as means $\pm \mathrm{SD}(\mathrm{C}) .{ }^{* * *} P<0.001$. CGA, chromogranin A; NCAM, neural cell adhesion molecule; si, small interfering; SYP, synaptophysin.

phospho-histone $\mathrm{H} 3$, Bcl-2, caspase-3, and cyclin D1, but increased cleaved caspase 3 (Figure 4C). In addition, a significant difference of proliferative activity was observed between the $\operatorname{Dox}^{-}$and Dox ${ }^{+}$tumors by counting Ki-67-labeled cells $\left(\right.$ Dox $^{-}$versus Dox ${ }^{+}, 77.6 \pm 6.2$ versus $33.2 \pm 9.2 ; N=5 ; P<0.01$ ) (Figure 4D). These findings suggest that the forced expression of INSM1 in NSCLC cell lines suppresses cell proliferation activity and induces apoptotic activity. On the other hand, in the SCLC cell lines, knockdown of INSM1 expression decreased Bcl-2, but increased phospho-histone $\mathrm{H} 3$ and cleaved caspase 3 . These findings suggest that knockdown of INSM1 expression facilitated the apoptotic pathway, but increased cell proliferative activity (Figure 4E). In the present study, the facilitated apoptotic activation seemed to be greater than the proliferative activity. The results of the cell counting assay could be explained by these results (Figure 4F).

\section{Effects of ASCL1 and BRN2 in Lung Cancer Cells}

We also conducted knockdown of ASCL1 and BRN2 expression in $\mathrm{H} 69$ and $\mathrm{H} 889$ cells, and transient transfection of ASCL1 and BRN2 in H358 and H1975 cells, to confirm the effects of ASCL1 and BRN2 in lung cancer cells. Knockdown or forced expression of ASCL1 and BRN2 did not affect INSM1 expression at all, suggesting that INSM1 is not regulated by ASCL1 and BRN2 (Figures 5 and 6). CGA and SYP protein expression was significantly suppressed by the knockdown of ASCL1 and BRN2 in H69 and H889 cells, but NCAM expression was slightly decreased, suggesting the existence of various pathways (Figure 5A and Figure 6A). NE molecules (CGA, SYP, and NCAM) were up-regulated in ASCL1-transfected H358 and H1975 cells at the protein level (Figure 5B). Meanwhile, the protein expression of NE molecules was not detected, but their mRNA was up-regulated in BRN2-transfected H358 and H1975 cells (Figure 6, B and C). These findings indicate that ASCL1 is a more crucial regulator for NE molecules than BRN2. The impact of ASCL1 on BRN2 expression was heterogeneous. BRN2 protein expression was significantly decreased in the H69 cells transfected with small interfering (si)ASCL1 (Figure 5A), and ASCL1 protein expression was slightly decreased in H69 cells transfected with siBRN2 (Figure 6A), suggesting that there is a mutual interaction between these two molecules in $\mathrm{H} 69$ cells. On the other hand, there seems to be no interaction of ASCL1 and BRN2 in H889 cells (Figure 5A and Figure 6A). In NSCLC cell lines, ASCL1 mRNA expression was increased in the $B R N 2$-transfected $\mathrm{H} 358$ cells, but was not affected in the BRN2-transfected H1975 cells (Figure 6C). Meanwhile, BRN2 mRNA expression level was increased in ASCL1-transfected H1975 cells, but was not affected in ASCL1-transfected H358 cells (Figure 5C). Therefore, the transcriptional program driven by ASCL1 is heterogeneous, as previously reported. ${ }^{33}$ The present results demonstrate that ASCL1 seems to have a stronger effect on the regulation of NE differentiation than BRN2, even though BRN2 also regulates the NE molecules' mRNA; furthermore, INSM1 should be considered as an upstream regulator for ASCL1, BRN2, and NE molecules in lung cancer cells. It has been shown that the knockdown of ASCL1 induces growth inhibition and apoptosis in SCLC cell lines ${ }^{17}$; however, the significance of BRN2 in SCLC on cell growth has not been clarified. In SCLC cell lines (H69 and H889), knockdown of BRN2 had no effects on cell proliferation and apoptosis in $\mathrm{H} 69$; in contrast, the 

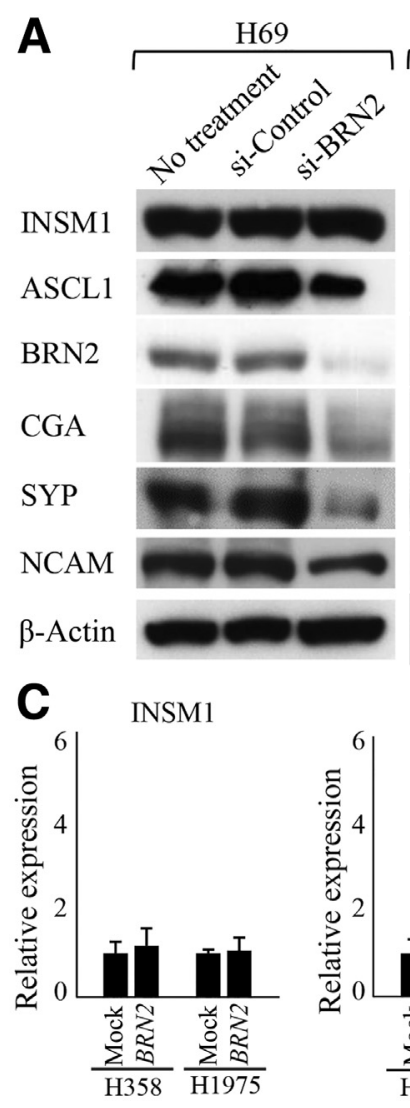

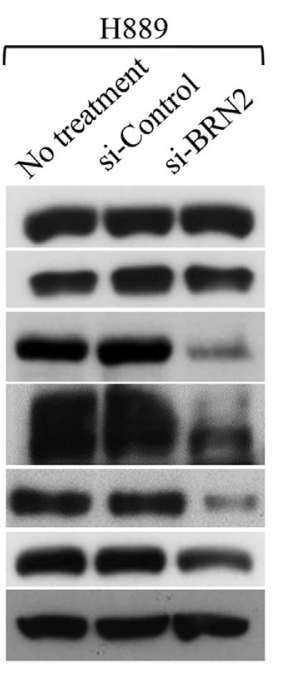

$\mathbf{B}$
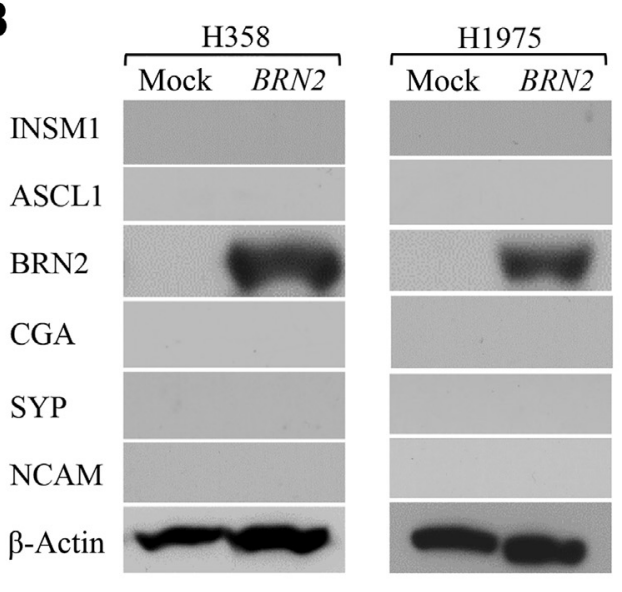

CGA
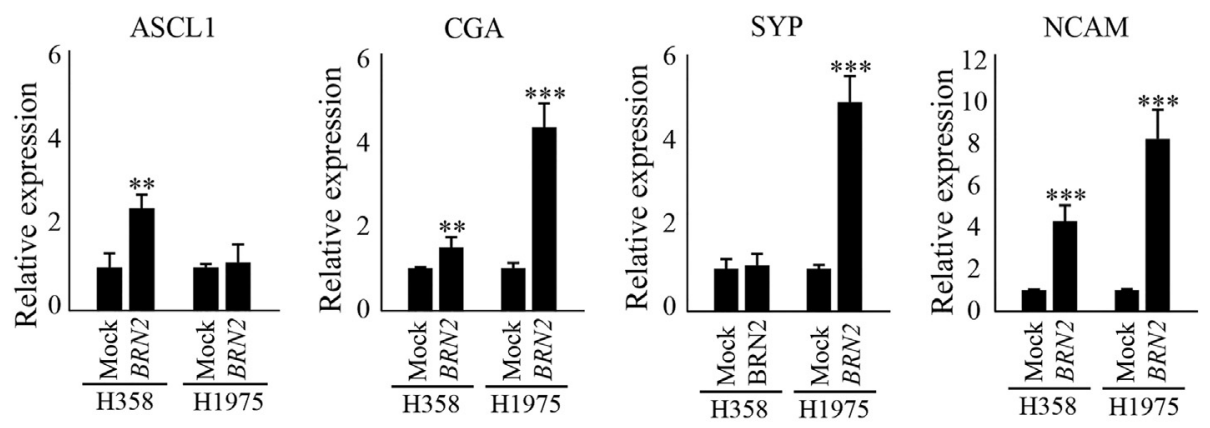

Figure 6 Brain-2 (BRN2) does not affect insulinoma-associated protein 1 (INSM1) expression, but is involved in the expression of neuroendocrine (NE) molecules and achaete-scute homolog-like 1 (ASCL1) in the lung cancer cell lines. BRN2 was knocked down or transiently expressed in lung cancer cell lines. All analyses were performed in triplicate. $\beta$-Actin was used as an internal control in Western blot (WB), whereas glyceraldehyde-3-phosphate dehydrogenase was also used in quantitative RT-PCR (RT-qPCR) analysis. A: The NE marker molecules [chromogranin A (CGA), synaptophysin (SYP), and neural cell adhesion molecule (NCAM)] decrease by knockdown of the BRN2 gene in the small-cell lung carcinoma (SCLC) cell lines. ASCL1 expression is slightly decreased only in $\mathrm{H} 69$ treated with siBRN2. INSM1 does not change at all. B: WB analyses reveal that the forced expression of the BRN2 gene does not affect the expression of other NE molecules in the adenocarcinoma (ADC) cell lines. C: RT-qPCR analysis reveals that $B R N 2$ does not affect the expression of INSM1 mRNA in both cell lines. The expression of ASCL1, CGA, and NCAM mRNAs increases in H358 transfected with BRN2; on the other hand, the expression of CGA, SYP, and NCAM mRNA increases in H1975 transfected with BRN2. Data are given as means \pm SD (C). ${ }^{*} P<0.01$, $* * * P<0.001$. Si, small interfering.

apoptotic pathway was facilitated and cell growth was suppressed in H889 (Supplemental Figure S2).

\section{Effect of Notch1-Hes1 Signaling on INSM1, ASCL1, and BRN2}

The protein expression of INSM1 and Notch1 showed the opposite patterns from each other, suggesting that the Notch1 signaling pathway could regulate INSM1 expression and ASCL1 (Figure 1B). Notch1-Hes1 signaling was reported to work as an inhibitor of ASCL1 and NE features. ${ }^{11,17-19}$ To elucidate whether Notch1-Hes1 signaling can regulate the expression of INSM1, we conducted Notch1 or Hes 1 knockdown experiments using RNA interference in SCLC cell lines expressing Notch1 and Hes1 (H69AR and SBC3), and forced expression experiments in SCLC cell lines without the expression of Notch1 or Hes1 (H69 and H889) (Figure 1B). INSM1 was not induced in both H69AR and SBC3 cell lines transfected with siNotch1 (Figure 7A), but was expressed in only the H69AR cells transfected with siHes1 (Figure 7C). Forced expression of Notch1 or Hes1 significantly suppressed INSM1 expression, ASCL1, and BRN2 (Figure 7, B and D). We previously reported that forced expression of Notch1 resulted in the inhibition of SCLC growth. ${ }^{17}$ In the present study, we confirmed the effects of Notch1 and Hes1 on SCLC cell growth in supplemental experiments (Supplemental Figure S3). Forced expression of Notch1 or Hes1 in SCLC cell lines (H69 and H889) decreased phospho-histone $\mathrm{H} 3$ and Bcl-2, but increased cleaved caspase 3, suggesting that the proliferation was suppressed and the apoptotic pathway was facilitated, similar to the findings in a previous report. ${ }^{17}$ These findings demonstrated that Notch1-Hes1 signaling suppresses INSM1, ASCL1, and BRN2 in lung cancer cell lines, and forced expression of Notch1-Hes1 signaling inhibits cell growth in SCLC cell lines. 
A

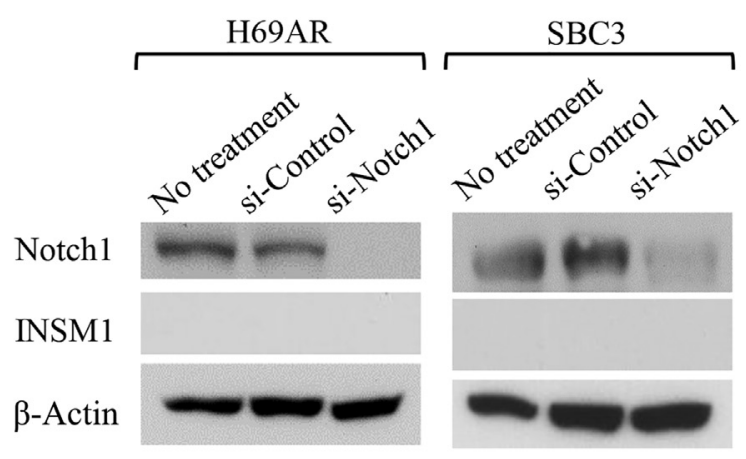

C

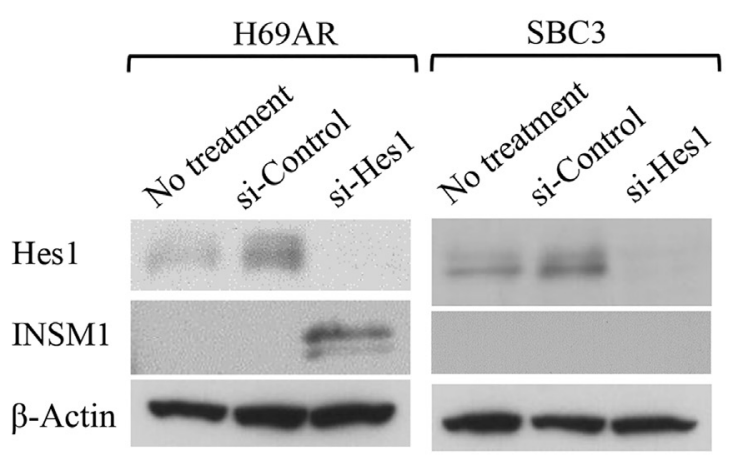

B

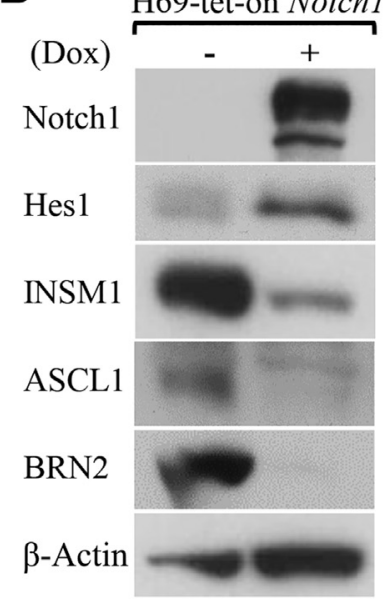

D

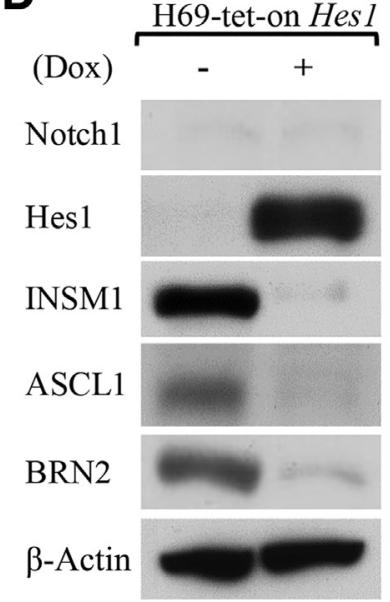

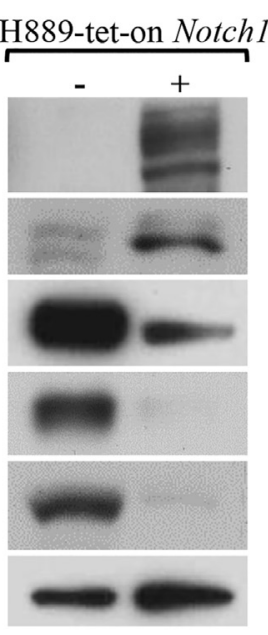

H889-tet-on Hes1

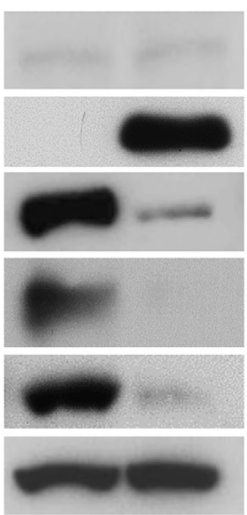

Figure 7 Notch1-hairy and enhancer of split-1 (Hes1) signaling suppresses insulinoma-associated protein 1 (INSM1), achaete-scute homolog-like 1 (ASCL1), and brain-2 (BRN2) expression. Knockdown experiments of Notch1 or Hes1 were conducted in two Notch1- and Hes1-expressing small-cell lung carcinoma (SCLC) cell lines (H69AR and SBC3). In addition, H69 and H889 SCLC cells, which do not have Notch1 and have slight expression of Hes1, were used for forced expression studies to determine the effects of Notch1 and Hes1 on the expression of INSM1, ASCL1, and BRN2. Tet-on Notch1 or Hes1 SCLC cells (H69-tet-on Notch1, H69-tet-on Hes1, H889-tet-on Notch1, and H889-tet-on Hes1), in which Notch1 or Hes1 appears on the presence of doxycycline (Dox), were established. In addition, the forced expression of Notch1 induced by Dox increases Hes1 and suppresses the expression of INSM1, ASCL1, and BRN2 in H69 and H889 cells. A: INSM1 is not detected in the H69AR and SBC3 cells by knockdown of the Notch1 gene. B: The forced expression of the Notch1 gene induced by Dox increases Hes1 and suppresses the expression of INSM1, ASCL1, and BRN2 in H69 and H889 cells. C: INSM1 appears in the H69AR cells on siHes1 RNA treatment, but does not in SBC3 treated with siHes1 mRNA. D: Overexpression of Hes1 induced by Dox significantly suppresses INSM1, ASCL1, and BRN2 in $\mathrm{H} 69$ and $\mathrm{H} 889$ cells. Note that Notch1 expression is not influenced by induced Hes1. Si, small interfering.

\section{Discussion}

The present study is the first to confirm that INSM1 is expressed exclusively in SCLC specimens using IHC staining and also the first to elucidate the significance of INSM1 in the NE differentiation of lung cancer cells. We herein revealed that INSM1 regulates ASCL1, BRN2, and NE molecules (CGA, SYP, and NCAM), and has a role in proliferation and apoptosis. SCLC is an aggressive and highly metastatic tumor with an extremely poor prognosis. Although usually responsive to chemotherapy, recurrent tumors almost always develop in a chemoresistance type. ${ }^{1,2}$ Therefore, an emphasis on elucidating the critical molecules that correlate with malignant biological behavior and on exploring therapeutic targets must be focused on in SCLC.
INSM1 is a zinc finger transcription factor originally isolated from a human insulinoma subtraction library. ${ }^{20}$ INSM1 expression is specific in NE tumors, including SCLC, pituitary tumor, pheochromocytoma, medullary thyroid carcinoma, neuroblastoma, and retinoblastoma. ${ }^{20,27,29}$ INSM1 is abundantly expressed in SCLC, but it is not detected after birth in normal adult lung tissue, implying the INSM1 expression could contribute to the SCLC characteristics. Although INSM1 was identified as a highly specific marker of SCLC, the molecular mechanism remained to be elucidated. ${ }^{9,10}$

Several lines of evidence have suggested that ASCL1 could promote $\mathrm{NE}$ tumorigenesis and be involved in the survival, growth, and acquisition of chemoresistance of SCLC; in addition, ASCL1 is reported as a therapeutic target of SCLC cell lines. ${ }^{12,13}$ ASCL1 is essential for the 


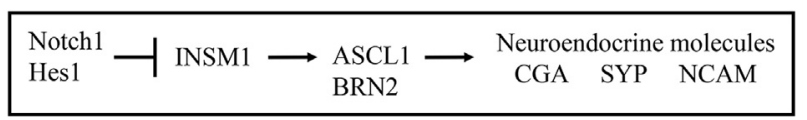

Figure 8 Molecular mechanisms in the neuroendocrine (NE) differentiation pathway of lung cancer cells. In lung cancer cells, NE differentiation is balanced between differentiation-suppressing transcription factors, such as Hes1, and differentiation-promoting transcription factors, such as insulinoma-associated protein 1 (INSM1) and achaete-scute homolog-like 1 (ASCL1), as seen in the normal lung epithelial system. The Notch1-Hes1 signaling pathway suppresses NE differentiation through the inhibition of transcription factors, such as INSM1 and ASCL1. Meanwhile, INSM1 promotes NE differentiation accompanying the enhanced expression of transcription factors, such as ASCL1 and BRN2. CGA, chromogranin A; NCAM, neural cell adhesion molecule; SYP, synaptophysin.

development of normal lung NE cells and other endocrine and neural tissues. ${ }^{11}$ Recently, INSM1 was reported as one of the gene targets in ASCL1-driving pathways. ${ }^{33}$ The present results demonstrated that the proteins of ASCL1 and NE molecules (CGA, SYP, and NCAM) and BRN2 mRNA expression levels were induced by forced expression of the INSM1 in NSCLC cell lines. In addition, the protein expression of ASCL1, BRN2, and NE molecules was significantly suppressed by knockdown of the INSM1 expression. We also confirmed that INSM1 binds to the promoter region of ASCL1 by using ChIP assay analysis. Thus, we concluded that INSM1 is an upstream regulator of ASCL1, and assumed that INSM1 function is exerted in the presence of ASCL1, because we observed INSM1 expression in the fetal lung of ASCL1-deficient mice (T.I., unpublished observation), in which no pulmonary NE cells are present. ${ }^{11}$ We also concluded that INSM1 is a regulator of the expression of BRN2 and NE molecules in lung cancer cell lines. Taking these findings together, INSM1 in SCLC is extremely important in various biological features.

NE molecules (CGA, SYP, and NCAM) are used as important complementary tools for the diagnosis of $\mathrm{NE}$ tumor of lung cancer. ${ }^{15}$ Several reports have suggested that the expression of these NE molecules contributes to SCLC malignancy. ${ }^{5-7}$ To extend previous findings of the expression of NE marker molecules in SCLC, ${ }^{30,31}$ we also investigated the effects of ASCL1 and BRN2 on the NE molecules' pathway. The present study showed that ASCL1 was involved in the protein expression of NE molecules. We could not detect the expression of the NE molecules by the forced expression of BRN2, but their mRNA levels were increased. BRN2 is a developmental neural cell-specific transcription factor that plays some role in maintaining the NE phenotype of SCLC with ASCL1. A few reports have indicated that BRN2 is a higher-level regulator of ASCL1. ${ }^{14}$ By forced knockdown experiments of BRN2, we found that the relationship between ASCL1 and BRN2 is heterogeneous. A mutual interaction was observed in H69 cells, but they were independent in $\mathrm{H} 889$ cells in regulating NE differentiation. Although the BRN2 mRNA expression level was increased by the forced expression of ASCL1 in H1975, the level of ASCL1 mRNA was increased by the forced expression of BRN2. These findings suggested that the mutual relationship between ASCL1 and BRN2 is complex. In addition, only INSM1 can regulate all of ASCL1, BRN2, and NE molecules constantly. As described, the present studies investigated the roles of three transcriptional factors in NE differentiation, and it is expected that these would contribute significantly to future SCLC research.

We also examined a xenotransplanted tumor with H358tet-on INSMI and H1975-tet-on INSM1. Although before the experiments we had imagined that forced expression of INSM1 could induce NE morphology, there were no histological differences between the Dox $^{-}$and Dox $^{+}$tumors. However, the induction of NE differentiation was confirmed by IHC staining in the tumor with the induction of INSM1 by Dox treatment. Presumably, INSM1 was not involved in lung cancer histology, but the contribution to NE differentiation was proved in vivo and in vitro.

Moreover, we found that INSM1 affected the cell proliferation and apoptosis of lung cancer cells. Little has been known about the effect of INSM1 on the proliferation of lung cancer cells. Xenotransplanted tumors with cells forced to express INSM1 were significantly smaller. In addition, we proved that the forced expression of INSM1 suppressed the cell proliferative activity and activated the apoptotic pathway in NSCLC cell lines. On the other hand, in SCLC cell lines, the knockdown of INSM1 expression resulted in the inhibition of cell growth and the activation of the apoptotic pathway. Therefore, we concluded that INSM1 could not only function as a regulator of the NE differentiation pathway, but also act as a regulator of cell growth. Although the effects of INSM1 on lung cancer cell lines varied depending on the cell type, knockdown of INSM1 expression suppressed NE differentiation and cell growth in SCLC, suggesting that INSM1 could be a target of SCLC treatment.

Several reports have indicated functional interactions between Notch1-Hes1 signaling and ASCL1, and we previously reported that Notch1 signaling suppresses ASCL1 and the NE molecules, and inhibits the cell growth of SCLC. ${ }^{17-19}$ However, to date, how INSM1 expression is regulated has remained unclear. Interestingly, in our WB study using lung cancer cell lines, those with Notch1 expression did not have INSM1 expression, and vice versa. In addition, all cases of surgically resected pure SCLC specimens and the SCLC component of combined SCLC specimens were negative for IHC staining for Notch1 (Supplemental Figure S1 and Table 3). Through the forced expression/knockdown of Notch1 or Hes1 experiments, we ascertained that Notch1-Hes1 signaling suppresses all of INSM1, ASCL1, and BRN2. Notably, Hes1, a key effector of the Notch signaling pathway, was considered as a stronger suppressor than Notch1, and different pathways from Notch1 could exist. This could explain why the protein expression of INSM1 was evident only by the knockdown of Hes1. In addition, we examined the IHC for Notch1 in the H358-tet-on INSM1 tumor xenograft model, but the expression of Notch1 did not differ between Dox ${ }^{-}$ and Dox ${ }^{+}$tumors (Supplemental Figure S4). These results 
support the assertion that Notch1 is an upstream regulator of INSM1 (Figure 8).

A high incidence of mutations in TP53 and RBI has been identified in small-cell carcinoma of the lung, ${ }^{34,35}$ and these bi-allelic TP53 and RBI lesions seem to be fundamental genetic events in small-cell carcinogenesis. This was confirmed by a mouse experimental study, in which smallcell carcinomas were induced in the lungs of mice deficient in $T p 53$ and $R b 1 .{ }^{36}$ Among these two genes, mutation or loss of $R B 1$ seems to be more characteristic in the development of small-cell carcinoma because RB1 was detected as the most decreased protein in small-cell carcinoma compared with non-small-cell carcinoma ${ }^{37}$ and because $R b l$ knockout mice show the proliferation of NE cells in the developing lungs. ${ }^{38}$ In the past 10 years, many cases with transformation from NSCLC to SCLC have been reported in one of the resistance mechanisms against EGFR tyrosine kinase inhibitors, and these tumors were approved as small-cell carcinoma by histology and IHC for NE markers. ${ }^{39}$ Interestingly, according to Niederst et al, ${ }^{40}$ all of the cases of transformation from ADC to small-cell carcinoma had loss of $R B 1$. In the present study, we analyzed NE differentiation from the viewpoints of transcriptional regulation and Notch signaling, but not from the viewpoint of genetic alterations, especially in $R B 1$. Although it has been reported that shRNA-mediated depletion of RB1 in EGFR mutant cancer cells resistant to an EGFR tyrosine kinase inhibitor did not induce NE differentiation, ${ }^{40}$ there should be underlying mechanisms between $R B 1$ mutations and NE differentiation that must be induced by the up-regulation of INSM1 and ASCL1 accompanying Notch1-Hes1 dysfunction.

In summary, SCLC exclusively overexpresses INSM1, and we demonstrated that INSM1 regulates the NE differentiation pathway represented by ASCL1, BRN2, and NE molecules (CGA, SYP, and NCAM) in lung cancer in vitro and in vivo (Figure 8 ). We also revealed the effects of INSM1 on the cell growth in lung cancer cell lines. Furthermore, we confirmed that the Notch1-Hes1 signaling pathway suppresses INSM1 expression. Further study of INSM1, considered as a crucial transcriptional factor involved in highly specific molecules in SCLC (ASCL1, BRN2, CGA, SYP, and NCAM), is needed. The present study promotes our understanding of the significance of INSM1 in SCLC, which will hopefully lead to the development of novel targeted therapies and an improved prognosis in SCLC.

\section{Acknowledgments}

We thank Motoko Kagayama, Takako Maeda, and Hiroko Kouzuma for their technical assistance; Dr. Adi F. Gazdar (University of Texas Southwestern Medical Center, Dallas, TX) for generously donating HCC15; and Prof. Seiji Okada (Kumamoto University, Kumamoto, Japan) for providing $\mathrm{Rag}^{-1-}: \mathrm{Jak}^{-/-}$mice.

\section{Supplemental Data}

Supplemental material for this article can be found at http://dx.doi.org/10.1016/j.ajpath.2015.08.018.

\section{References}

1. Kris MG, Benowitz SI, Adams S, Diller L, Ganz P, Kahlenberg MS, Le QT, Markman M, Masters GA, Newman L, Obel JC, Seidman AD, Smith SM, Vogelzang N, Petrelli NJ: Clinical cancer advances 2010: annual report on progress against cancer from the American Society of Clinical Oncology. J Clin Oncol 2010, 28:5327-5347

2. Rodriguez E, Lilenbaum RC: Small cell lung cancer: past, present, and future. Curr Oncol Rep 2010, 12:327-334

3. Mitsudomi T, Morita S, Yatabe Y, Negoro S, Okamoto I, Tsurutani J, Seto T, Satouchi M, Tada H, Hirashima T, Asami K, Katakami N, Takada M, Yoshioka H, Shibata K, Kudoh S, Shimizu E, Saito H, Toyooka S, Nakagawa K, Fukuoka M: Gefitinib versus cisplatin plus docetaxel in patients with non-small-cell lung cancer harbouring mutations of the epidermal growth factor receptor (WJTOG3405): an open label, randomised phase 3 trial. Lancet Oncol 2010, 11:121-128

4. Kwak EL, Bang YJ, Camidge DR, Shaw AT, Solomon B, Maki RG, Ou SH, Dezube BJ, Janne PA, Costa DB, Varella-Garcia M, Kim WH, Lynch TJ, Fidias P, Stubbs H, Engelman JA, Sequist LV, Tan W, Gandhi L, Mino-Kenudson M, Wei GC, Shreeve SM, Ratain MJ, Settleman J, Christensen JG, Haber DA, Wilner K, Salgia R, Shapiro GI, Clark JW, Iafrate AJ: Anaplastic lymphoma kinase inhibition in nonsmall-cell lung cancer. N Engl J Med 2010, 363:1693-1703

5. May M, Siegsmund M, Hammermann F, Loy V, Gunia S: Prognostic significance of proliferation activity and neuroendocrine differentiation to predict treatment failure after radical prostatectomy. Scand J Urol Nephrol 2007, 41:375-381

6. Linnoila RI, Zhao B, DeMayo JL, Nelkin BD, Baylin SB, DeMayo FJ, Ball DW: Constitutive achaete-scute homologue-1 promotes airway dysplasia and lung neuroendocrine tumors in transgenic mice. Cancer Res 2000, 60:4005-4009

7. Travis WD: Pathology and diagnosis of neuroendocrine tumors: lung neuroendocrine. Thorac Surg Clin 2014, 24:257-266

8. Ball DW, Azzoli CG, Baylin SB, Chi D, Dou S, Donis-Keller H, Cumaraswamy A, Borges M, Nelkin BD: Identification of a human achaete-scute homolog highly expressed in neuroendocrine tumors. Proc Natl Acad Sci U S A 1993, 90:5648-5652

9. Pedersen N, Mortensen S, Sorensen SB, Pedersen MW, Rieneck K, Bovin LF, Poulsen HS: Transcriptional gene expression profiling of small cell lung cancer cells. Cancer Res 2003, 63:1943-1953

10. Taniwaki M, Daigo Y, Ishikawa N, Takano A, Tsunoda T, Yasui W, Inai K, Kohno N, Nakamura Y: Gene expression profiles of small-cell lung cancers: molecular signatures of lung cancer. Int J Oncol 2006, 29:567-575

11. Ito T, Udaka N, Yazawa $T$, Okudela $K$, Hayashi $H$, Sudo $T$, Guillemot F, Kageyama R, Kitamura H: Basic helix-loop-helix transcription factors regulate the neuroendocrine differentiation of fetal mouse pulmonary epithelium. Development 2000, 127:3913-3921

12. Osada H, Tomida S, Yatabe Y, Tatematsu Y, Takeuchi T, Murakami H, Kondo Y, Sekido Y, Takahashi T: Roles of achaete-scute homologue 1 in DKK1 and E-cadherin repression and neuroendocrine differentiation in lung cancer. Cancer Res 2008, 68:1647-1655

13. Osada H, Tatematsu Y, Yatabe Y, Horio Y, Takahashi T: ASH1 gene is a specific therapeutic target for lung cancers with neuroendocrine features. Cancer Res 2005, 65:10680-10685

14. Ishii J, Sato H, Sakaeda M, Shishido-Hara Y, Hiramatsu C, Kamma H, Shimoyamada H, Fujiwara M, Endo T, Aoki I, Yazawa T: POU domain transcription factor BRN2 is crucial for expression of ASCL1, ND1 and neuroendocrine marker molecules and cell growth in small cell lung cancer. Pathol Int 2013, 63:158-168 
15. WHO Classification of Tumours of the Lung, Pleura, Thymus and Heart, $4^{\text {th }}$ Edition. Edited by Travis WD, Brambilla E, Burke AP, Marx A, Nicholson AG. Lyon, France, IARC, 2015, pp. 63-68

16. Hamanaka W, Motoi N, Ishikawa S, Ushijima M, Inamura $\mathrm{K}$, Hatano S, Uehara H, Okumura S, Nakagawa K, Nishio M, Horai T, Aburatani H, Matsuura M, Iwasaki A, Ishikawa Y: A subset of small cell lung cancer with low neuroendocrine expression and good prognosis: a comparison study of surgical and inoperable cases with biopsy. Hum Pathol 2014, 45:1045-1056

17. Wael H, Yoshida R, Kudoh S, Hasegawa K, Niimori-Kita K, Ito T: Notch1 signaling controls cell proliferation, apoptosis and differentiation in lung carcinoma. Lung Cancer 2014, 85:131-140

18. Shan L, Aster JC, Sklar J, Sunday ME: Notch-1 regulates pulmonary neuroendocrine cell differentiation in cell lines and in transgenic mice. Am J Physiol Lung Cell Mol Physiol 2007, 292:L500-L509

19. Sriuranpong V, Borges MW, Strock CL, Nakakura EK, Watkins DN, Blaumueller CM, Nelkin BD, Ball DW: Notch signaling induces rapid degradation of achaete-scute homolog 1. Mol Cell Biol 2002, 22: 3129-3139

20. Goto Y, De Silva MG, Toscani A, Prabhakar BS, Notkins AL, Lan MS: A novel human insulinoma-associated cDNA, IA-1, encodes a protein with "zinc-finger" DNA-binding motifs. J Biol Chem 1992, 267:15252-15257

21. Gierl MS, Karoulias N, Wende H, Strehle M, Birchmeier C: The zincfinger factor Insm1 (IA-1) is essential for the development of pancreatic beta cells and intestinal endocrine cells. Genes Dev 2006, 20:2465-2478

22. Wildner H, Gierl MS, Strehle M, Pla P, Birchmeier C: Insm1 (IA-1) is a crucial component of the transcriptional network that controls differentiation of the sympatho-adrenal lineage. Development 2008, 135: $473-481$

23. Rosenbaum JN, Duggan A, Garcia-Anoveros J: Insm1 promotes the transition of olfactory progenitors from apical and proliferative to basal, terminally dividing and neuronogenic. Neural Dev 2011, 6:6

24. Farkas LM, Haffner C, Giger T, Khaitovich P, Nowick K, Birchmeier C, Paabo S, Huttner WB: Insulinoma-associated 1 has a panneurogenic role and promotes the generation and expansion of basal progenitors in the developing mouse neocortex. Neuron 2008, 60:40-55

25. Xie J, Cai T, Zhang H, Lan MS, Notkins AL: The zinc-finger transcription factor INSM1 is expressed during embryo development and interacts with the Cbl-associated protein. Genomics 2002, 80:54-61

26. Zhu M, Breslin MB, Lan MS: Expression of a novel zinc-finger cDNA, IA-1, is associated with rat AR42J cells differentiation into insulinpositive cells. Pancreas 2002, 24:139-145

27. Breslin MB, Zhu M, Lan MS: NeuroD1/E47 regulates the E-box element of a novel zinc finger transcription factor, IA-1, in developing nervous system. J Biol Chem 2003, 278:38991-38997

28. Lan MS, Breslin MB: Structure, expression, and biological function of INSM1 transcription factor in neuroendocrine differentiation. FASEB J 2009, 23:2024-2033

29. Lan MS, Russell EK, Lu J, Johnson BE, Notkins AL: IA-1, a new marker for neuroendocrine differentiation in human lung cancer cell lines. Cancer Res 1993, 53:4169-4171
30. Christensen CL, Gjetting T, Poulsen TT, Cramer F, Roth JA, Poulsen HS: Targeted cytosine deaminase-uracil phosphoribosyl transferase suicide gene therapy induces small cell lung cancer-specific cytotoxicity and tumor growth delay. Clin Cancer Res 2010, 16: 2308-2319

31. Michaelsen SR, Christensen CL, Sehested M, Cramer F, Poulsen TT, Patterson AV, Poulsen HS: Single agent- and combination treatment with two targeted suicide gene therapy systems is effective in chemoresistant small cell lung cancer cells. J Gene Med 2012, 14: $445-458$

32. Yoshida R, Nagata M, Nakayama H, Niimori-Kita K, Hassan W, Tanaka T, Shinohara M, Ito T: The pathological significance of Notch1 in oral squamous cell carcinoma. Lab Invest 2013, 93:1068-1081

33. Augustyn A, Borromeo M, Wang T, Fujimoto J, Shao C, Dospoy PD, Lee V, Tan C, Sullivan JP, Larsen JE, Girard L, Behrens C, Wistuba II, Xie Y, Cobb MH, Gazdar AF, Johnson JE, Minna JD: ASCL1 is a lineage oncogene providing therapeutic targets for high-grade neuroendocrine lung cancers. Proc Natl Acad Sci U S A 2014, 111: $14788-14793$

34. Peifer M, Fernández-Cuesta L, Sos ML, George J, Seidel D, Kasper LH, et al: Integrative genome analyses identify key somatic driver mutations of small-cell lung cancer. Nat Genet 2012, 44: $1104-1110$

35. Rudin CM, Durinck S, Stawiski EW, Poirier JT, Modrusan Z, Shames DS, et al: Comprehensive genomic analysis identifies SOX2 as a frequently amplified gene in small-cell lung cancer. Nat Genet 2012, 44:1111-1116

36. Meuwissen R, Linn SC, Linnoila RI, Zevenhoven J, Mooi WJ, Berns A: Induction of small cell lung cancer by somatic inactivation of both Trp53 and Rb1 in a conditional mouse model. Cancer Cell 2003, 4:181-189

37. Byers LA, Wang J, Nilsson MB, Fujimoto J, Saintigny P, Yordy J, Giri U, Peyton M, Fan YH, Diao L, Masrorpour F, Shen L, Liu W, Duchemann B, Tumula P, Bhardwaj V, Welsh J, Weber S, Glisson BS, Kalhor N, Wistuba II, Girard L, Lippman SM, Mills GB, Coombes KR, Weinstein JN, Minna JD, Heymach JV: Proteomic profiling identifies dysregulated pathways in small cell lung cancer and novel therapeutic targets including PARP1. Cancer Discov 2012, 2: 798-811

38. Wikenheiser-Brokamp KA: Rb family proteins differentially regulate distinct cell lineages during epithelial development. Development 2004, 131:4299-4310

39. Oser MG, Niederst MJ, Sequist LV, Engelman JA: Transformation from non-small-cell lung cancer to small-cell lung cancer: molecular drivers and cells of origin. Lancet Oncol 2015, 16:e165-e172

40. Niederst MJ, Sequist LV, Poirier JT, Mermel CH, Lockerman EL, Garcia AR, Katayama R, Costa C, Ross KN, Moran T, Howe E, Fulton LE, Mulvey HE, Bernardo LA, Mohamoud F, Miyoshi N, VanderLaan PA, Costa DB, Jänne PA, Borger DR, Ramaswamy S, Shioda T, Iafrate AJ, Getz G, Rudin CM, Mino-Kenudson M, Engelman JA: RB loss in resistant EGFR mutant lung adenocarcinomas that transform to small-cell lung cancer. Nat Commun 2015, 6: 6377 